\title{
Spatiotemporal Colonization of Xylella fastidiosa in its Vector Supports the Role of Egestion in the Inoculation Mechanism of Foregut-Borne Plant Pathogens
}

\author{
Elaine A. Backus and David J. W. Morgan
}

First author: United States Department of Agriculture-Agricultural Research Service, San Joaquin Valley Agricultural Sciences Center, 9611 So. Riverbend Ave, Parlier, CA 93648; and second author: California Department of Food and Agriculture, Mt. Rubidoux Field Station, 4500 Glenwood Dr., Bldg. E, Riverside, CA 92501.

Accepted for publication 18 March 2011.

\begin{abstract}
Backus, E. A., and Morgan, D. J. W. 2011. Spatiotemporal colonization of Xylella fastidiosa in its vector supports the role of egestion in the inoculation mechanism of foregut-borne plant pathogens. Phytopathology 101:912-922.

The pathogen that causes Pierce's disease of grapevine, Xylella fastidiosa, is the only known bacterial, arthropod-transmitted plant pathogen that does not circulate in the vector's hemolymph. Instead, bacteria are foregut-borne, persistent in adult vectors but semipersistent in immatures (i.e., bacteria colonize cuticular surfaces of the anterior foregut, are retained for hours to days, but are lost during molting). Yet, exactly how a sharpshooter vector inoculates bacteria from foregut acquisition sites is unknown. The present study used confocal laserscanning microscopy to identify locations in undissected, anterior foreguts of the glassy-winged sharpshooter colonized by green fluorescent protein-expressing $X$. fastidiosa. Spatial and temporal distributions

laboratory-reared Homalodisca vitripennis. Results provide the first direct, empirical evidence that established populations of $X$. fastidiosa can disappear from vector foreguts over time. When combined with existing knowledge on behavior, physiology, and functional anatomy of sharpshooter feeding, present results support the idea that the disappearance is caused by outward fluid flow (egestion) not inward flow (ingestion) (i.e., swallowing). Thus, results support the hypothesis that egestion is a critical part of the $X$. fastidiosa inoculation mechanism. Furthermore, results suggest a cyclical, spatiotemporal pattern of microbial colonization, disappearance, and recolonization in the precibarium. Colonization patterns also support two types of egestion, termed rinsing and discharging egestion herein. Finally, comparison of acquisition results for field-collected versus laboratory-reared sharpshooters suggest that there may be competitive binding for optimum acquisition sites in the foregut. Therefore, successful inoculation of $X$. fastidiosa may depend, in large part, on vector load in the precibarium.
\end{abstract} of colonizing $X$. fastidiosa were examined daily over acquisition access periods of 1 to 6 days for both contaminated field-collected and clean

Xylella fastidiosa, causative agent of Pierce's disease of grapevine and several other leaf scorch diseases, is a gram-negative, xylem-limited bacterium that has a unique relationship with its xylem-feeding sharpshooter vectors. $X$. fastidiosa is the only known arthropod-transmitted plant pathogen that is propagative (multiplies in its vector) without being circulative in the insect's hemolymph (19). Instead, bacteria colonize the cuticular surface of the oral cavity (anterior foregut) $(1,8,26)$. This part of the gut consists of the precibarium (a narrow channel conveying fluid from the stylets to the pump) and the cibarium (sucking pump). Pathogens retained in these sites are termed foregut-borne (21).

$X$. fastidiosa is also the only bacterial plant pathogen that is primarily semipersistently vector-transmitted (i.e., acquired and inoculated). Because $X$. fastidiosa is propagative in the foregut, it is uniquely persistent in adult vectors, because adults do not molt. Yet, in all other ways, $X$. fastidiosa fits the definition of Fereres and Moreno (15) for semipersistent transmission. In other words,

Corresponding author: E. Backus; E-mail address: elaine.backus@ars.usda.gov

Mention of trade names or commercial products in this article is solely for the purpose of providing specific information and does not imply recommendation or endorsement by the United States Department of Agriculture.

doi:10.1094/PHYTO-09-10-0231

This article is in the public domain and not copyrightable. It may be freely reprinted with customary crediting of the source. The American Phytopathological Society, 2011.
Additional keywords: microbial competition, transmission mechanism.

$X$. fastidiosa (i) has no latent period in the vector, (ii) is retained in the vector for longer than a few hours yet (iii) cannot be recovered from vector hemolymph (nor can the insect inoculate it following injection into its hemolymph), and (iv) loses inoculativity from immature vectors following molting because the pathogen cells attached to the molted cuticle are lost (21). Semipersistent transmission is rare for plant pathogens transmitted by non-aphid hemipterans; the only other known cases are Maize chlorotic dwarf virus, Rice tungro spherical virus (both Waikiviridae), and Rice tungro bacilliform virus (Caulimoviridae), all of which are nonpropagative and transmitted by leafhoppers (Hemiptera: Cicadellidae) in the subfamily Deltocephalinae (15). Sharpshooters are leafhoppers in the subfamily Cicadellinae.

Combined, the above traits for semipersistent, foregut-borne transmission indicate that $X$. fastidiosa is inoculated directly into a plant from retention sites in the precibarium or cibarium. Yet exactly how the insect expels bacteria from these sites is still unknown. This is in spite of nearly 70 years of extensive study of $X$. fastidiosa transmission biology (11). Most progress to date is attributable to the relatively large sizes of both the bacteria and sharpshooters (compared with viruses and their much smaller deltocephaline vectors) that readily allows microscopic examination of colonization sites in the foregut. As a result, $X$. fastidiosa transmission is the best-studied model system for semipersistent, foregut-borne pathogen transmission.

The last 30 years of research progress from scanning electron microscopy (SEM) studies of foregut colonization was reviewed in detail in Almeida and Purcell (1). In summary, foregut 
colonization of several sharpshooter species was demonstrated by the mid-1980s, including the dominant model species, blue-green sharpshooter Graphocephala atropunctata (Say) (26), as well as the subject of the present study, glassy-winged sharpshooter Homalodisca vitripennis (Takiya) (then, H. coagulata) (8). In between these two studies, Backus and McLean (5) hypothesized that $X$. fastidiosa inoculation occurred from the precibarium. They also proposed that the precibarial valve (a hinged, flap-like structure in the middle of the precibarium) was somehow involved. Brlansky et al. $(8,9)$ hypothesized valve malfunction due to bacterial clogging, although they did not present evidence for this hypothesis.

In 1995, Hill and Purcell (19) showed that G. atropunctata adults with thousands of bacteria in their foreguts could inoculate as efficiently as those with only a single cell. They proposed that inoculation might occur from a very small area in the foregut, although they did not directly reference the precibarium. In support of that hypothesis, Almeida and Purcell (1) found that $X$. fastidiosa inoculation of grape was highly correlated with colonization of the precibarium in G. atropunctata, especially the area proximal to the precibarial valve.

During the same time period as these $X$. fastidiosa microscopy studies, debate about mechanisms of nonpersistent virus transmission generated a number of hypotheses equally relevant to foregut-borne, semipersistent transmission. One of the most notable was Harris's ingestion-egestion hypothesis for virus acquisition and inoculation, respectively (16), which introduced the concept that plant fluid flow into vector stylets could occasionally reverse, so that fluid could flow out of the stylets. This fluid was at first thought to be regurgitant from the midgut (17), until it was realized that the esophageal valve would prevent such outflow; thereafter, its source was proposed to be the foregut, and the outflow was termed egestion $(16,18)$. Today, the ingestionegestion hypothesis has been mostly supplanted by the ingestionsalivation hypothesis (24) as the likely transmission mechanism of both non- and semipersistent viruses recently shown to be stylet-tip-borne by aphids $(7,27)$. However, evidence continues to support egestion as a likely inoculation mechanism for semipersistent pathogens that are either known to be or are putatively foregut-borne by leafhoppers $(15,28)$. No one, however, has identified exactly how egestion would work and how it could propel bacteria from the stylets.

The technology of microscopy has greatly improved in the last 30 years, especially with the introduction of confocal laserscanning microscopy (CLSM). Past studies of $X$. fastidiosa colonization in vector foreguts used SEM; however, this process entails dissection and separation of the cuticular plates (pharynges) inside the vector's head that compose the anterior foregut, potentially disturbing the in situ locations of the bacteria. For the first time, optical sectioning capabilities of CLSM have made possible the direct observation of in situ bacteria within the undisturbed, undissected foreguts of vectors.

Accordingly, the objectives of this study were to determine (i) locations colonized by $X$. fastidiosa located in situ in intact, anterior foreguts of $H$. vitripennis over time spans representative of typical acquisition access periods (AAPs); (ii) whether spatial and temporal distribution of acquired $X$. fastidiosa differed between field-collected and laboratory-reared $H$. vitripennis; (iii) whether these findings supported the hypothesis that egestion is part of the $X$. fastidiosa inoculation mechanism and, if so, how it might operate; and (iv) whether evidence of the inoculation mechanism could inform our understanding of vector efficiency and its role in Pierce's disease epidemiology.

\section{MATERIALS AND METHODS}

$X$. fastidiosa culture. The $X$. fastidiosa Temecula strain, transformed to express green fluorescent protein (GFP) (23), was provided by S. Lindow (University of California, Berkeley). Bacteria were maintained on standard periwinkle wilt medium (12) modified with Gel-Rite for solidification. Bacterial cultures were maintained at $28^{\circ} \mathrm{C}$, according to methods previously described (10).

Sharpshooter collection and rearing. Laboratory-reared $H$. vitripennis were originally collected on citrus at Agricultural Operations on the University of California, Riverside (UCR) campus in late summer. Insects were subsequently reared for multiple generations in greenhouses at either of two sites: (i) UCR (the UCR colony) on cowpea (Vigna unguiculata (L.)) and sorghum (Sorghum bicolor (L.)) plants in the same cage, maintained at 24 to $29^{\circ} \mathrm{C}$ (16 and $8 \mathrm{~h}$ of light and darkness, respectively) (for surveys only, see Experimental Design, below) or (ii) the Mt. Rubidoux Field Station, California Department of Food and Agriculture (CDFA), Riverside (the CDFA colony), on a mixture of sweet basil (Ocimum basilicum (L)), sorghum, and sunflower (Helianthus annuus (L.)) plants in the same cage, under similar conditions (for surveys and experiment 1, see Experimental Design, below). The $X$. fastidiosa infection status of host plants for UCR-reared sharpshooters was unknown. In contrast, the CDFA colony of sharpshooters was continuously reared on uninfected host plants for $\approx 30$ generations, and was likely to be noninoculative (D. J. W. Morgan, unpublished data). Young adults were transported from both experimental colonies to a United States Department of Agriculture quarantine facility in Fresno, $\mathrm{CA}$, then caged on the same species of uninfected host plants under artificial lights for $\approx 1$ to 8 days until used for surveys or experiments. All transport into quarantined counties was previously approved under CDFA permit.

Field-collected $H$. vitripennis (for surveys and experiment 2; see Experimental Design, below) were swept from ornamental plants along roadways in Bakersfield, CA, in late summer, and transported directly to the quarantine facility in Fresno. Insects were maintained for several days on a mixture of cowpea, sweet basil, and sorghum plants in the same cage, under similar conditions as above, until prepared for microscopy (for surveys) or moved to an acquisition cage (for experiments). Rearing plants were grown in a Parlier, CA greenhouse supplemented with artificial lighting, at the same temperature and photoperiod, and brought to the Fresno facility as needed. All studied sharpshooters were young female or male adults.

Grapevine rearing and inoculation with $X$. fastidiosa. Grapevines ( $V$. vinifera 'Cabernet sauvignon') for $X$. fastidiosa acquisition feeding were grown in the Parlier greenhouse from rooted canes (Foundation Plant Services, Davis, CA) until at least four to six mature leaves had developed. Stems were then needle (mechanically) inoculated (using insulin syringes) with a total of 0.1 to $0.2 \mathrm{ml}$ of cultured $X$. fastidiosa GFP $\left(10^{6}\right.$ to $\left.10^{8} \mathrm{CFU} / \mathrm{ml}\right)$ at multiple sites along one to four stems of each plant. Inoculated grapevines were held at 24 to $29^{\circ} \mathrm{C}$ and a photoperiod of 16 and 8 $\mathrm{h}$ (light and darkness, respectively) for 3 to 6 months with automated drip irrigation for standardized watering, until strong symptoms of Pierce's disease developed (i.e., match-sticking of petioles, internode shortening, and leaf scorching) and polymerase chain reaction (PCR) tests (10) detected the presence of $X$. fastidiosa. If an inoculated grapevine did not show symptoms after 3 to 4 months, it was inoculated a second time. Infected plants were transported to the Fresno quarantine facility, where they were used for sharpshooter acquisition of $X$. fastidiosa (experiments 1 and 2, below).

Experimental design. Surveys: pre-acquisition microbial distribution. To determine the benchmark degree of microbial contamination of the sharpshooter anterior foregut prior to acquisition of $X$. fastidiosa GFP during experiments (below), surveys of the above-described field-collected versus laboratoryreared $H$. vitripennis were performed. Four to eight insects from each population described above were prepared and examined 
using either SEM or CLSM. Combining both types of microscopy, 12 field-collected sharpshooters and 15 laboratory-reared sharpshooters ( 11 from UCR and 4 from CDFA) were examined for the presence or absence and location of microbes in the cibarium or the precibarium. As a result of these surveys, the CDFA colony was chosen for the laboratory-reared insects for experiment 1 (below).

Experiments: post-acquisition microbial distribution. To determine how varying AAPs for $X$. fastidiosa GFP facilitated colonization of the foregut, in all, 60 sharpshooters laboratory-reared at CDFA (experiment 1) and 48 sharpshooters field-collected from Bakersfield (experiment 2) were separately caged on two or three infected, symptomatic grapevines. Each AAP day, 10 laboratoryreared or 8 field-collected insects were removed from the acquisition cages for daily AAPs of 1 to 6 days. Intact foreguts were dissected, examined, and imaged using CLSM alone for presence, absence, and location of $X$. fastidiosa and other microbes. A smaller number of field-collected insects was used because fewer were available at the time than laboratory-reared ones. In addition, 4 to 10 insects each were held for longer AAPs of $\leq 10$ days. However, only partial results from those specimens were included in the study because the specimens were found to be contaminated with wild-type microbes after later microscopic examination. This was due to sudden, catastrophic contamination of the formerly clean CDFA colony near the end of experiment 1.

SEM. Using the method of Backus and McLean $(5,6), H$. vitripennis heads were excised from bodies, fixed in $4 \%$ (vol/vol) glutaraldehyde (Electron Microscopy Sciences [EMS], Hatfield, PA), then held in same until dehydrated and critical point dried (Tousimis, Rockville, MO). Working under a Leica ML12.5 (Wetzlar, Germany) stereoscan microscope and with each dried head held on a vacuum stand, the epipharyngeal and hypopharyngeal plates that together form the precibarium and cibarium (6) were gently teased apart and separately mounted on SEM stubs using copper tape (EMS). In some cases, dried microbial biofilm could be seen adhered to the foregut cuticle, with no visible dislodging. In a few rare cases, when large amounts of biofilm were present, excess, loosely attached material filling the precibarial lumen occasionally became dislodged and lost in the dissection process (as was also the rare case for studies by Backus et al. [4]). Mounted specimens were sputter coated with a goldpalladium mix using a Cressington 208HR sputter coater (Watford, UK). Stubs were examined and imaged using a Hitachi scanning electron microscope (Model S-3500N; Schaumburg, IL) and edited in Adobe Photoshop CS2 (San Jose, CA).

CLSM. Similar to above, $H$. vitripennis heads were excised from bodies under 4\% (vol/vol) paraformaldehyde (EMS) and held in the same until dissected to reveal the intact cibarium and precibarium. Dissections were made carefully to avoid separation of the epi- and hypopharyngeal plates and to provide undisturbed, in situ visualization of $X$. fastidiosa GFP in the interior of the foregut. Tissues were mounted in glycerine with $0.5 \%$ ascorbic acid (as an anti-fade agent) on microscope slides with gaskets (EMS), then examined, optically sectioned, and imaged on a Leica acoustic-optical beam splitter (AOBS) SP2 confocal microscope using Leica Confocal Software.

CLSM spectral separation of $X$. fastidiosa GFP from unknown, wild-type microbes in field-collected sharpshooters relied upon three criteria. First, the Leica AOBS adjustable system of wavelength detection allows highly specific spectral separation, independently settable by the operator, in contrast to preset physical filters of most CLSM microscopes. We narrowed the GFP detection window such that there was no overlap with the emission spectrum of the autofluorescence, while still detecting the majority of GFP signal. The 488-nm Ar/ArKr and 633-nm HeNe lasers were used; PMT 1 was programmed for the 494- to 511-nm range to visualize the $X$. fastidiosa GFP, while PMT 2 was programmed for the 520- to 591-nm range to visualize autofluorescence of the insect cuticle and wild-type microbes, which were false-colored red. Reliable separation of wild-type microbes from insect cuticle was achieved via the second and third criteria. The second was brightness (i.e., the three-dimensional texture of wild-type microbes against smooth insect cuticle created greater depth for contrast, allowing microbes to stand out and appear brighter red in images). The third was that all suspected microbes in both wavelength ranges were checked at high magnification, to ensure that their structure resembled clumps of bacillar or spherical microbes and not artifacts such as backscatter shine from the insect cuticle. Thus, the combination of highly specific spectral separation by the AOBS, three-dimensional texture, and the physical shape criteria made our confocal imaging as accurate as SEM imaging of microbes.

Overview images were made at low magnification $(100 \times)$ of the entire, step-like foregut area and at several points along the walls and base of the cibarium. At each imaged location, two to four images were taken at a higher magnification to show important details. Z-stack optical scanning through the depth of biofilm was performed to localize small amounts of $X$. fastidiosa GFP embedded within wild-type microbes for mixed colonization. Images were further edited for contrast and clarity using Adobe Photoshop CS2.

Statistical analysis of data from experiments. The amount of $X$. fastidiosa GFP present in each laboratory-reared insect in or near six anatomical features defined as locations in the foregut (Fig. 1A; cibarium plus five precibarial locations) was estimated as none $=0$, low $=1$, medium $=2$, or high $=3$, by comparison among the high-magnification CLSM images for each insect. Ranks for amount (density) of $X$. fastidiosa GFP were then averaged across the insects for each daily AAP. Standard errors were calculated and analysis of variance (ANOVA; Proc GLM; SAS, Cary, NC) was performed $(\alpha=0.05)$ for density rankings in the cibarium only; density rankings among locations in the precibarium were too variable among the small samples size of insects to perform ANOVA on those data. Frequencies (i.e., probabilities) of occurrence of bacteria for each cibarial or precibarial location were also calculated as percentage of total number of insects with any amount of bacteria present in each location. The total number of insects varied between 7 and 10 for each location because some insects were not represented in the sample for that foregut location, due to occasional preparation artifacts.

\section{RESULTS}

Surveys: pre-acquisition images. SEM. Three-dimensional SEM images revealed that all $H$. vitripennis from the CDFA colony (i.e., laboratory-reared for nearly 30 generations on uninfected plant material at CDFA Riverside) were completely clean of any contaminating microbial biofilm (Fig. 1A). This image of the epipharyngeal side reveals the architectural fine structure of part of the cibarium (uppermost in the image) and all of the precibarium; the figure is labeled to present terminology not previously published, which will be used hereafter. The uppermost (in the image), anatomically proximal section of the precibarium, nearest the cibarium, is termed the epipharyngeal or hypopharyngeal (as appropriate) trough (Fig. 1A and D). It is mostly a straight channel, although lined with cuticular ridges that probably aid fluid flow. Distal to the trough (lower, in the image) is the epipharyngeal basin, a rounded structure with deep groves in the center and on the edges, whose two sides house three each of the proximal (P-) precibarial chemosensilla (6). The distal end of the basin is marked by the precibarial pit, which is actually the open end of the tendon-like apodeme (cuticular invagination) that lifts the precibarial valve (Fig. 1A) via the underlying valve muscle (5). When relaxed, the valve rests in the groove of the basin. Distal to the pit (below in Fig. 1A) is the wide, flat area 
that houses the 10 distal (D-) precibarial chemosensilla. This area is hereafter termed the D-sensilla field.

SEM images of all insects from the UCR colony (i.e., laboratory-reared for a few generations) plus all field-collected sharpshooters showed moderate to large depths of microbial biofilm covering most exposed surfaces of cibarium and precibarium (Fig. $1 \mathrm{~B}$ to D). The cibarium was consistently coated with dense biofilm forming a fibrillar matrix (Fig. 1B, top), which often extended into the trough of the precibarium (Fig. 2A). Tears in the fibrillar matrix revealed rod-shaped bacteria resembling $X$. fastidiosa (similar to Fig. 2D), as well as spherical (Fig. 2E) or pleomorphous (Fig. 2F) microbes of unknown type. The precibarium was usually partially to wholly occluded with accumulations of similar biofilm but often spatially segregated into different locations. The main part of the trough (distal to the opening into the cibarium) was usually empty or, if colonized, sometimes was filled with large, roughly round microbes of unknown type (Fig. 1C). Below the trough, the basin was often clogged, or fully occluded, with chunks of material or bright fibrillar matrix that resembled that in the cibarium (Fig. 1B and D), or gelatinous blobs with smoothly rounded microbes of unknown type (Fig. 2B and E). Usually, the valve was not completely hidden by biofilm; however, sometimes it appeared to be secured open by accumulations of unknown microbes that filled most of the basin (Fig. 2B), especially in field-collected insects. Accumulations in the Dsensilla field were uncommon regardless of the source (colony type or field) for the insect or, if present, biofilm over the Dsensilla was much less dense (Fig. 2C).

CLSM. CLSM images of $H$. vitripennis were qualitatively similar to those using SEM. Cibarial biofilm from field-collected and UCR-reared sharpshooters showed large fibrillar aggregations of wild-type microbes (false-colored red) that often resembled those of X. fastidiosa GFP (green) (compare Fig. 3A and B). In contrast, all CDFA-reared insects were clean and uncontaminated (Fig. 4, days 1 and 5, D-sensilla field).

An attempt was made to develop a protocol to process and examine the same sharpshooter head using first CLSM followed by SEM, to correlate the appearances of putative $X$. fastidiosa (wild type, non-GFP) using both methods. However, the protocol did not capture the desired correlation. Because our confocal imaging was highly accurate in detecting microbes (see CLSM section, above), we are certain that large amounts of $X$. fastidiosa-

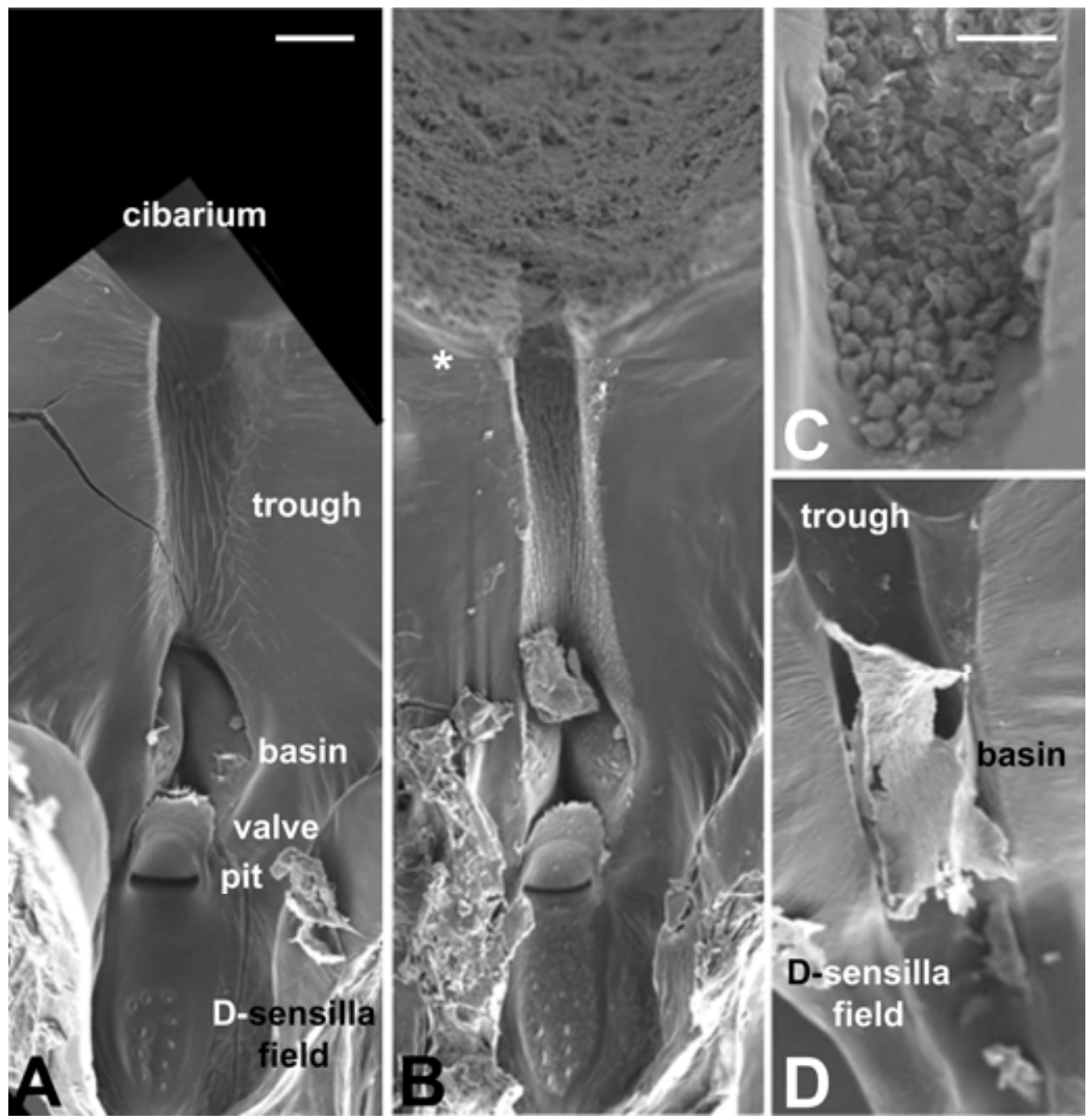

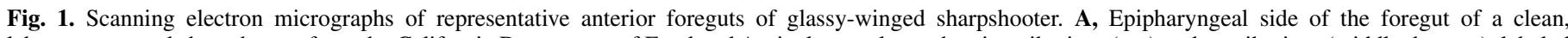

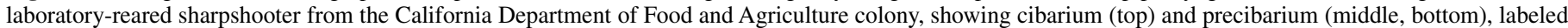

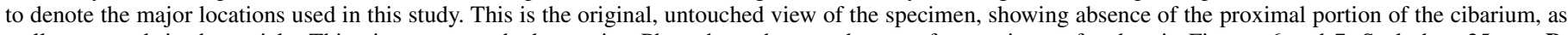

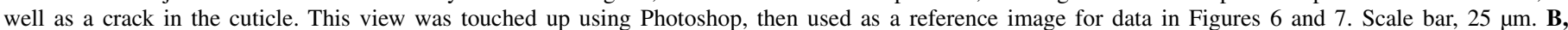

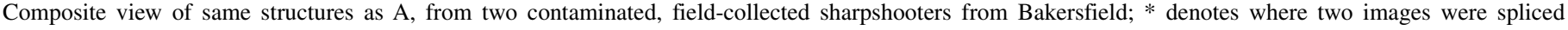

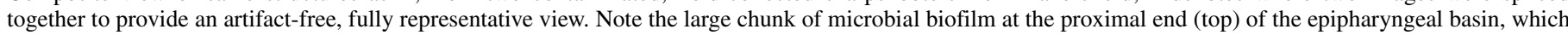

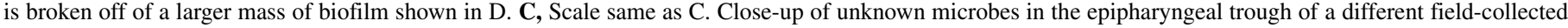

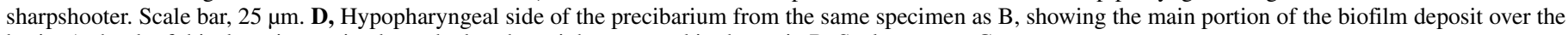
basin. A chunk of this deposit remained attached to the epipharynx, and is shown in B. Scale same as C. 
like bacterial biofilm was seen in the CLSM images (Fig. 3A); yet it was nearly absent from the SEM images (Fig. 3D). We have previously observed that glycerine causes $X$. fastidiosa GFP biofilm to detach from insect cuticle. Therefore, it is likely that bacteria were loosened by glycerine during CLSM processing and were then rinsed away during dehydration for SEM.

Experiment 1: time course of acquisition by clean, laboratory-reared sharpshooters. Three representative CLSM images of X. fastidiosa GFP for each of the six locations (cibarium, trough, basin and valve [including pit], and D-sensilla field), for representative AAPs of 1, 3, and 5 days are shown in Figure 4 (columns 2 to 4). Bright greenish-yellow X. fastidiosa GFP is visible against the darker, crimson-red autofluorescence of the insect cuticle. Generally similar results occurred for all 60 individual insects. Within the first $24 \mathrm{~h}, X$. fastidiosa GFP was apparent throughout the cibarium, whereas the amount varied with location and AAP day in areas of the precibarium. There was consistently a lower amount of $X$. fastidiosa GFP in all insects on day 5 (Fig. 4, column 4).

Mean rank (per insect) of $X$. fastidiosa GFP density in each of six locations (i.e., cibarium, trough, basin, valve, pit, and Dsensilla field) is graphed as a stacked bar chart (Fig. 5) for all six daily AAPs. For every AAP, even within $24 \mathrm{~h}$ of placement on infected grape, the cibarium had the highest $X$. fastidiosa GFP density rank among foregut locations. Overall, there was a barely significant difference for cibarial densities among all AAPs $(F=$ 3.65 , df $=1,56, P=0.0611$ ). When the mean density rank for day 1 was compared with that for day 2 , they were highly significantly different $(F=25.59$, df $=1,17, P<0.0001)$, while comparison among days 2 to 6 showed no significant difference ( $F=1083$, df $=1,47, P=0.1821)$. Therefore, density of $X$. fastidiosa GFP in the cibarium was significantly lower on day 1
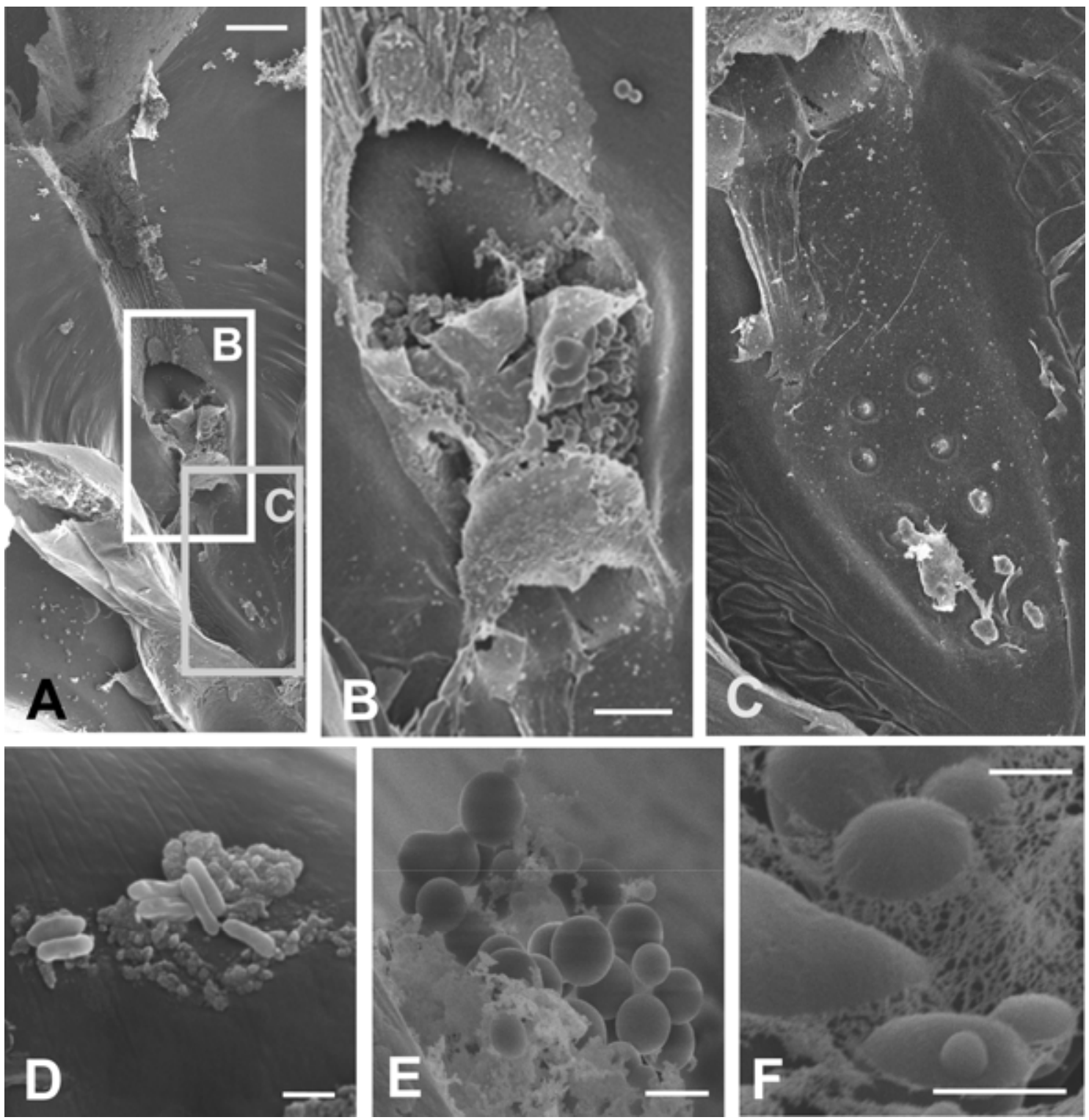

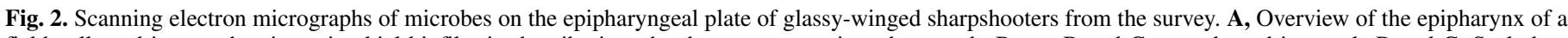

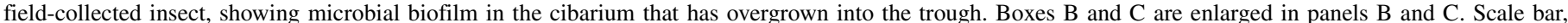

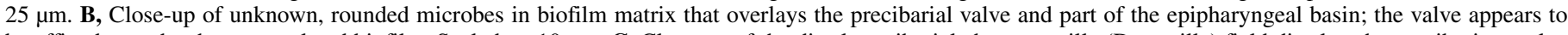

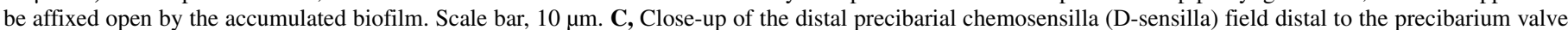

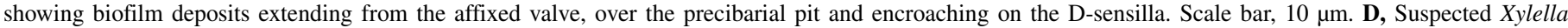

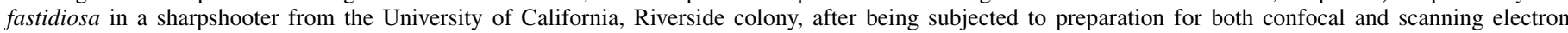

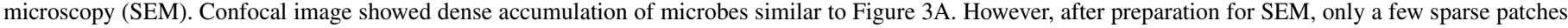

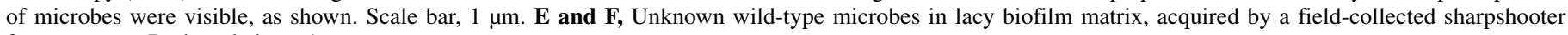
from a survey. Both scale bars, $1 \mu \mathrm{m}$. 
than other days, increasing to a level that remained the same for every AAP thereafter (Fig. 5). In contrast, mean $X$. fastidiosa GFP density ranks were highly unstable in the precibarium, across varying locations and AAPs. In most locations, the mean density rank increased for the first 3 days' AAP; the ranks then rapidly declined for days 4 and 5, and then began again to build up on day 6 (Fig. 5).

A similar pattern of build-up-then-decline was seen with probability (frequency) data (i.e., percentage of insects exhibiting any amount of bacteria in each location), as portrayed visually in Figure 6. Within the first $24 \mathrm{~h}$, all insects had X. fastidiosa GFP in their cibaria; this frequency continued throughout the six days' AAPs (Fig. 6). In contrast, not all insects had bacteria in their precibarium on any given AAP day. The distribution supports both a spatial and temporal pattern of bacterial colonization and reproduction from the cibarium distad (downward in Fig. 6) into the precibarium, with colonization first of the trough and parts of the basin (day 1), then adding the rest of the basin and valve (day 2), and finally adding the D-sensilla field below the valve (days 2 to 3). Then, strikingly, progress reversed, and probability of bacterial occupancy in the precibarium abruptly declined on day 4 , until bacteria were virtually absent from all insects on day 5 . The only bacteria found in the precibarium on day 5 were (apparently residual populations) in the deepest cracks of the pit and the fold along the top edge of the basin. On day 6, once again the trough and upper basin were more frequently colonized, suggesting another distad progression of bacterial growth from the cibarium. It was also striking that virtually no $X$. fastidiosa GFP colonization occurred distal to the precibarial valve; only 7 of 50 insects had any bacteria in that location and only on days 2 , 3 , and 6.

Experiment 2: time course of acquisition by contaminated, field-collected sharpshooters. Field-collected insects given daily AAPs on $X$. fastidiosa GFP-infected grape developed mixed colonies of wild-type microbes and $X$. fastidiosa GFP (Fig. 3C and D). Presumably, wild-type microbes were acquired in the field first and $X$. fastidios $a$ GFP were acquired second, during the laboratory AAPs. The detectable amount of $X$. fastidiosa GFP acquired was highly variable, ranging from only a tiny amount (barely detectable against the bright, ruby red of the wild-type microbes in the background) (Fig. 3C) to significant amounts that stood out from the bright red background (Fig. 3D). In some cases, the $X$. fastidiosa GFP were interspersed in the middle of a vertical column of wild-type bacterial biofilm in an individual location. In other cases, the $X$. fastidiosa GFP were layered on top of the red biofilm. An attempt to prepare CLSM-viewed speci- mens and examine them a second time, via SEM, revealed typical appearance of $X$. fastidiosa bacterial cells (Fig. 3E).

Due to reduced amounts of $X$. fastidiosa GFP and variability in contrast levels between microbial and cuticular autofluorescence (causing lower resolution), it was not possible to rank the density of wild-type bacteria present, as was done with $X$. fastidiosa GFP for experiment 1 (Fig. 5). However, frequency data (probability of occupancy) similar to experiment 1 were collected, and are portrayed in Figure 7 in a manner similar to Figure 6. Once again, a very similar pattern of microbial colonization occurred: (i) early and frequent accumulation of wild-type microbes in the cibarium; (ii) increasing accumulation of microbes distad into the precibarium over the first 2 days' AAPs, including below the precibarial valve; (iii) gradual decrease (day 3), then near-disappearance of the microbes (day 4) from the precibarium, including below the valve; and then (iv) gradual increase in microbe populations again (days 5 and 6).

The probability of occupancy of $X$. fastidiosa GFP in the mixed colony was higher in the cibarium than anywhere in the precibarium (wherein it was very low). Also, like the wild-type microbes, $X$. fastidiosa GFP increased in area, then abruptly decreased. When found in the precibarium, the $X$. fastidiosa GFP was never seen in the trough, more frequently seen in the basin and on the valve, and, in the D-sensilla field, seen only in a single individual insect (out of 48, on day 1). The pattern of appearance and disappearance of the $X$. fastidiosa GFP followed closely that of the wild-type microbes and disappearance of $X$. fastidiosa GFP even seemed to precede that of wild-type microbes in some rare cases.

Three to four specimens for each AAP in days 7 to 10 from experiment 1 were also examined; all were found to be severely contaminated with wild-type microbes. Their mixed colonies of red microbes with $X$. fastidiosa GFP exhibited spatiotemporal patterns of colonization similar to those from experiment 2 . Interestingly, specimens from days 7 and 10 resembled those from days 2 and 3 from experiment 2; they had the highest probabilities of bacterial occupancy. In contrast, day 8 and 9 insects resembled day 4 specimens from experiment 2; they had the lowest probabilities and appeared swept clean. This strongly suggests that the 2- to 3-day cycle of colonization and disappearance continued beyond AAP day 6.

\section{DISCUSSION}

Our study began by asking: do spatial colonization patterns of $X$. fastidiosa in sharpshooter foreguts change over time? Such change is a prediction of the egestion-salivation hypothesis for the
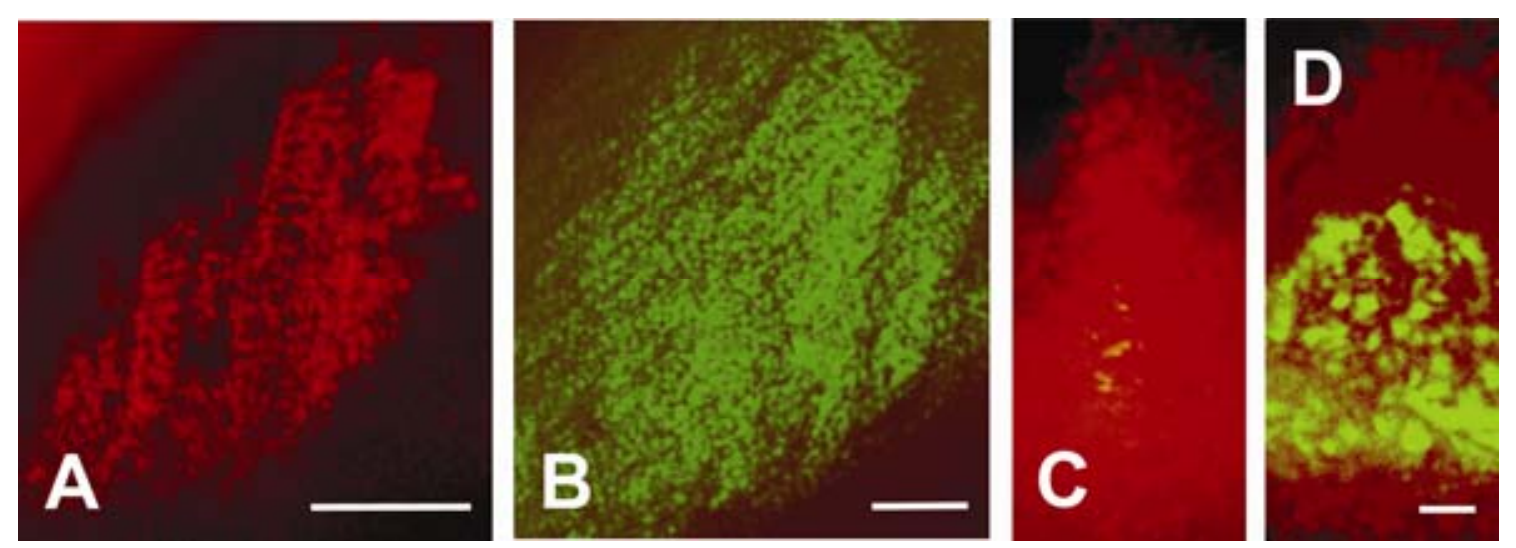

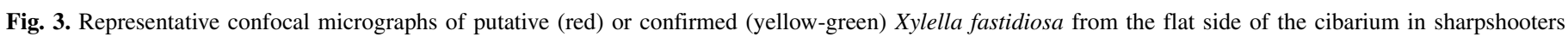

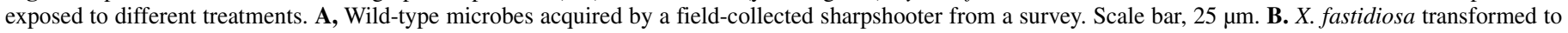

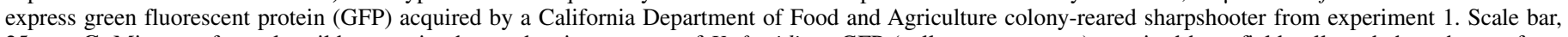

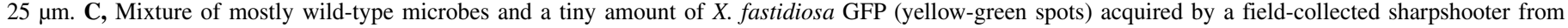

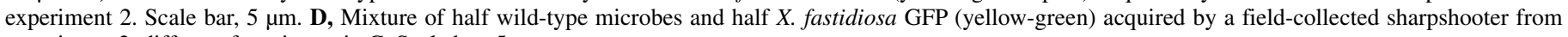
experiment 2, different from insect in C. Scale bar, $5 \mu \mathrm{m}$. 
inoculation mechanism of $X$. fastidiosa (4) and other semipersistent, foregut-borne pathogens. Results strongly support change over time and also provide evidence that the pattern of precibarial colonization is both nonlinear and cyclical.

In the case of $X$. fastidiosa acquisition by "clean," laboratoryreared sharpshooters, results from this study support three interpretations. First, X. fastidiosa GFP rapidly and completely colonized the cibarium within 24 to $48 \mathrm{~h}$ of access to infected grape. The cibarium then became a stable reservoir of $X$. fastidiosa GFP, from which bacteria loaded progressively distad into the precibarium during the first 2 days. Second, colonization of the D-sensilla field (distal to the precibarial valve) was usually prevented. This finding is supported by previous studies (1) and observations (E. A. Backus, unpublished data), in which $X$. fastidiosa usually was found only proximal to the precibarial valve. We propose that distal colonization of the precibarium is prevented by turbulent rinsing of the D-sensilla field by a functional precibarial valve (see further details below). However, once areas proximal to the valve had completely filled with $X$. fastidiosa GFP, at approximately day 3, the probability of bacterial colonization distal to the valve greatly increased (because the mechanism that had prevented colonization was no longer functioning). Third, on days 4 and 5, the accumulated $X$. fastidiosa GFP biofilm in the precibarium was rapidly swept away (discharged), while still retaining the colony in the cibarium; all but the most deeply sequestered bacterial cells were removed. Progressive colonization from the cibarial reservoir then began again on day 6 .

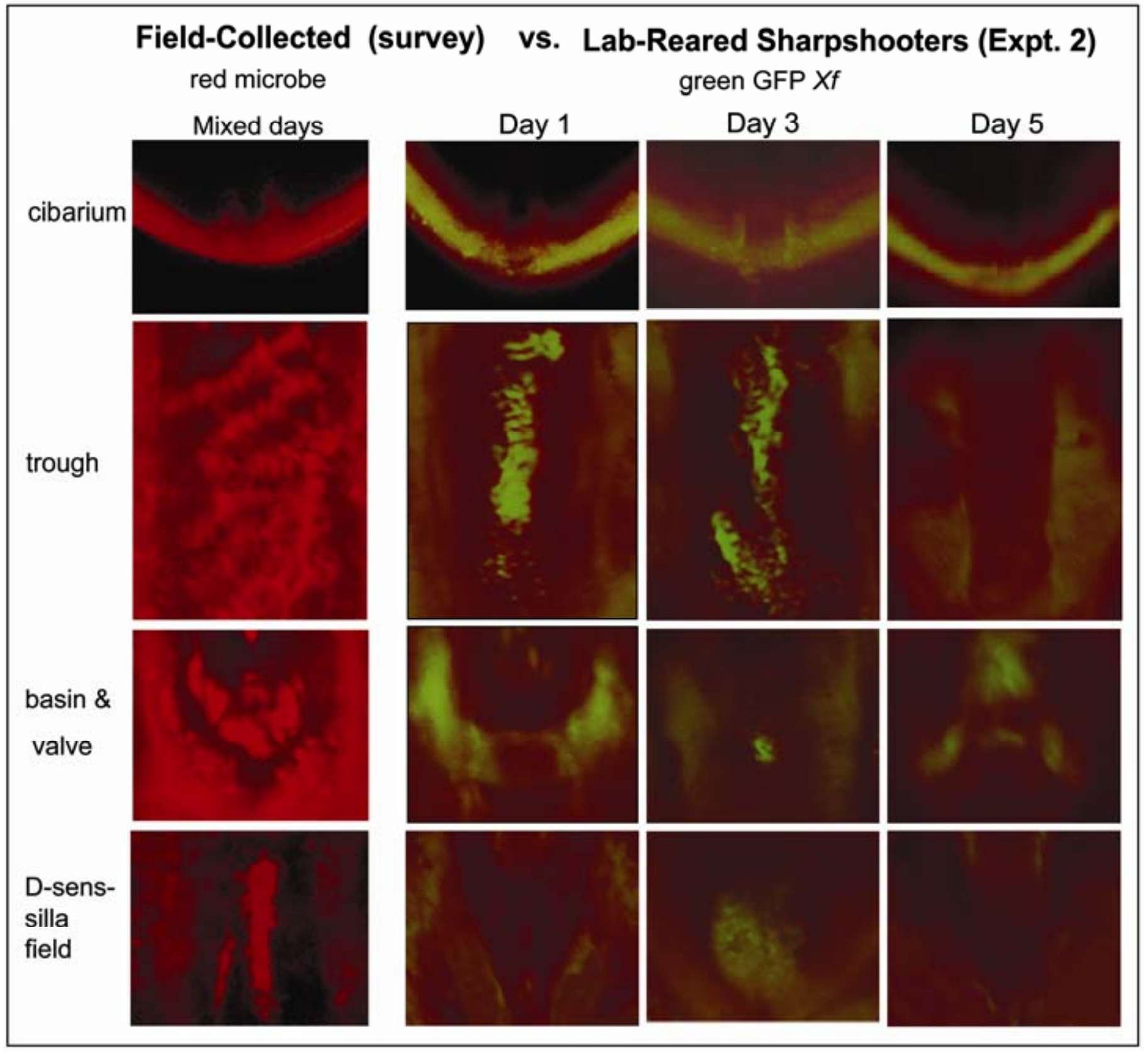

Fig. 4. Representative confocal micrographs showing actual appearances of wild-type microbes or Xylella fastidiosa transformed to express green fluorescent protein (GFP) in six major locations in undissected sharpshooter foreguts. Cibarial images show an optical cross-section through the side walls of the cibarium, near the opening to the precibarium. All other images are optical saggital sections through the plane of the precibarium housing that location. Column 1: "Red" wild-type microbes, from various acquisition access period (AAP) days, to demonstrate the contrast between dark crimson (cuticle) and bright ruby red (microbe). Columns 2 to 4: X. fastidiosa GFP in the various foregut locations on AAP days 1 (column 2), 3 (column 3), and 5 (column 4). Absence of microbes always resembled images such as the trough, day 5; basin and valve, day 3 (but lacking the tiny green X. fastidiosa in the center); and distal precibarial chemosensilla (D-sensilla) field, days 1 and 5 . 


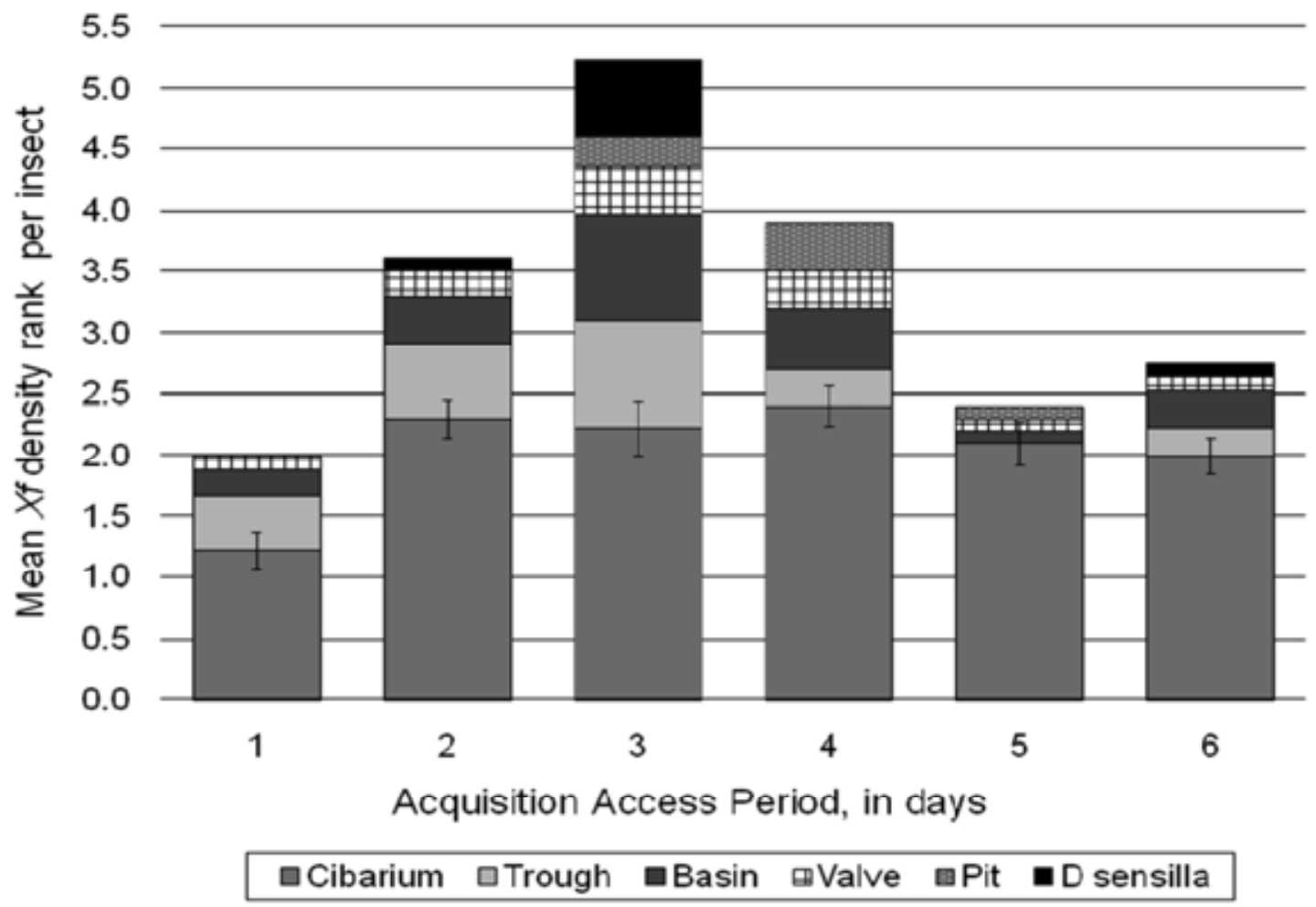

Fig. 5. Means per insect for density ranks of Xylella fastidiosa transformed to express green fluorescent protein (GFP) for each of the 6 days of acquisition access period for laboratory-reared Homalodisca vitripennis (experiment 1).

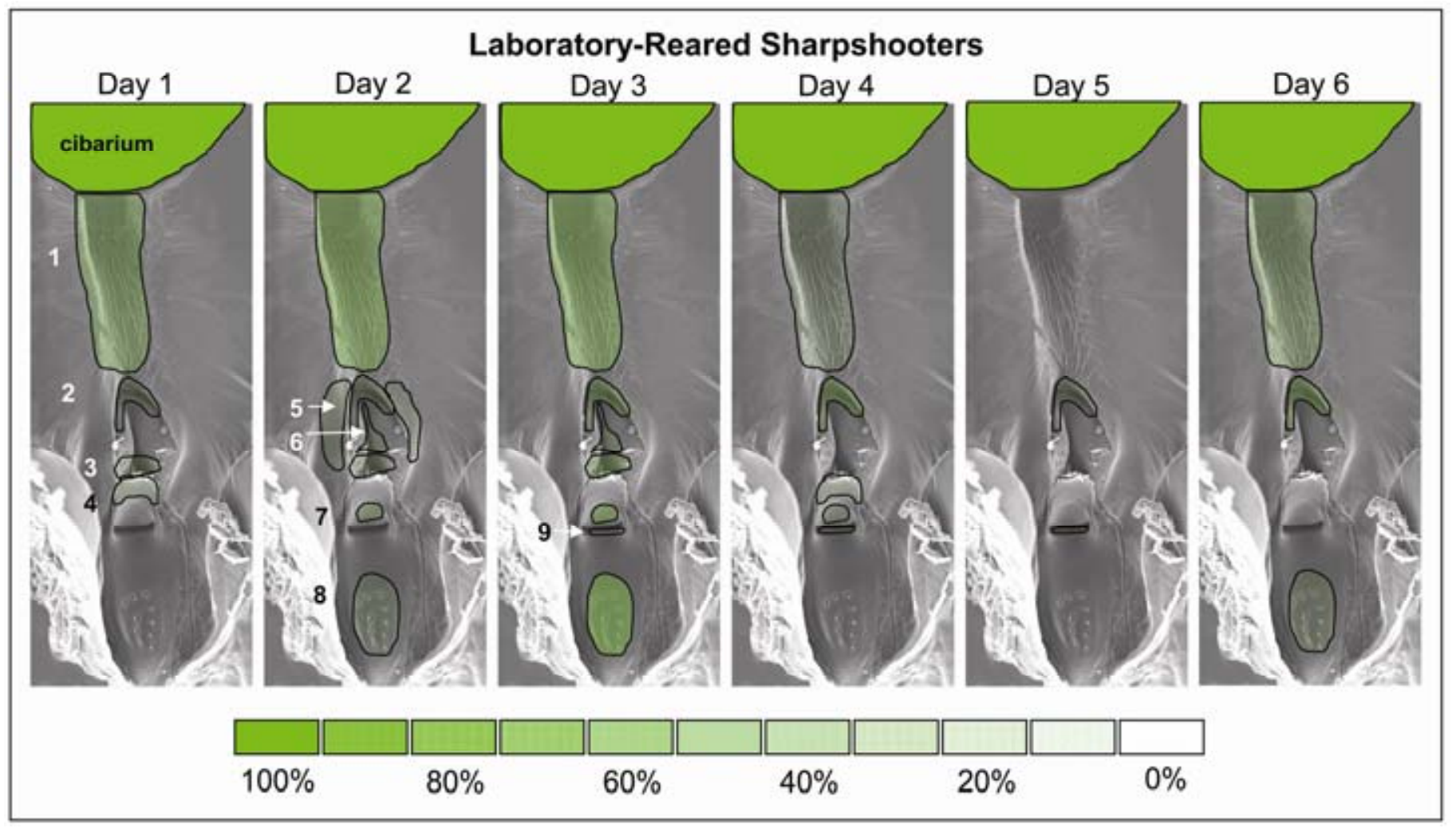

Fig. 6. Pictorial representation of the percentage of 10 laboratory-reared sharpshooters (experiment 1 ) for each acquisition access period that showed any amount of bacteria in each location in the precibarium or cibarium. Data are visually portrayed by green shapes superimposed over the clean image from Figure 1A, as an anatomical reference. Degree of transparency of shape denotes percentage, as shown in the key on the bottom. For example, the most opaque area (the cibarium) had a probability of $100 \%$ occupancy, whereas the most transparent green area (under the precibarial valve, day 4 ) had a probability of $10 \%$ occupancy. Each shape represents one of nine different locations (labeled in images for days 1,2, and 3); that is, cibarium, trough (number 1); groove at the proximal (upper) end of the basin (number 2); groove in the basin just above the precibarial valve (number 3); space under the valve (number 4); protuberances on the upper edge of the basin (number 5); bottom of the central groove of the basin (number 6); top of the valve near the precibarial pit (number 7); distal precibarial chemosensilla (D-sensilla) field (number 8); and precibarial pit (number 9). 
In contrast, for $X$. fastidiosa GFP acquisition by contaminated field-collected sharpshooters, the distribution of $X$. fastidios $a$ GFP was best summarized by the phrase "last in, first out." In our experiment, wild-type microbes were well established in the same locations that the $X$. fastidiosa GFP would have occupied (as determined with the laboratory-reared insects), because they had been the "first in" to colonize the foregut and apparently occupied the same locations as $X$. fastidiosa GFP. Therefore, $X$. fastidiosa GFP acquired during the experiment was the "last in"-appearing to colonize the small amounts of space remaining, sometimes on the surface or embedded within the wild-type biofilm. When virtually all microbes disappeared from the foregut on day 4 , the $X$. fastidiosa GFP was probably swept out first, because it was completely removed; in contrast, a larger amount of the wild-type microbes remained behind ("last out"). However, by day 5, both the wild-type and $X$. fastidios $a$ GFP colonies were reestablishing.

Anatomical or physiological mechanisms of egestion. When the present findings are combined with previous work on sharpshooter feeding behavior (4) and functional anatomy or physiology of cibarial pumping (14), disappearance of bacteria from the precibarium is readily explainable. Microbes are scrubbed from precibarial binding sites via specific mechanical actions of the precibarial valve and cibarial pump that push fluid distad from the sharpshooter cibarium and precibarium into the stylet food canal, and eventually out into the environment external to the insect (14). The action of expelling fluid in this manner is termed egestion $(16,18)$ or extravasation $(20,28)$; herein, we use the former term.

Our evidence also suggests that two new, hypothesized egestion processes occur in leafhoppers and probably other hemipterans: (i) rinsing egestion and (ii) discharging egestion. We hypothesize that rinsing egestion is responsible for the lack of accumulations in the D-sensilla field. This scrubbing occurs during normal, unimpeded sharpshooter feeding, caused by turbulent fluid currents from movements of the precibarial valve. Thus, small amounts of bacterial biofilm are ejected whenever the valve moves during stylet penetration, especially during tasting of both xylem and non-xylem cells by the precibarial chemosensilla. We further postulate that discharging egestion is responsible for the less common emptying of the entire length of the precibarium, and is performed to clear obstructions of the valve and precibarial chemosensilla caused by microbial build-up. Discharging egestion is caused by sudden, snap-like release of the cibarial diaphragm (the "lid" of the cibarial pump) before the cibarium is full of fluid (prior to swallowing) (14) to forcefully propel fluid into the precibarium and out of the stylets. This would only occur if the precibarial valve were affixed open and were unable to passively close, as it does during swallowing (14). Discharging egestion may occur most often in xylem cells, possibly aided by negative tension of the xylem fluid. Thus, discharging egestion may be the most etiologically important mechanism of inoculation.

Implications for the inoculation mechanism of $X$. fastidiosa. Here, we provide the first direct, empirical evidence that established colonies of $X$. fastidiosa and other microbes in the sharpshooter precibarium can disappear and reappear over time in a cyclical manner. Although not definitive, this study, in combination with previous results described above, supports the idea that outward fluid flow (egestion), not inward (ingestion), expels bacteria from the stylets. Egestion has long been hypothesized to be a mechanism of inoculation of $X$. fastidiosa $(5,6,25)$ and other foregut-borne plant pathogens $(15,22)$. Nonetheless, evidence for egestion in inoculation of $X$. fastidiosa has been tenuous.

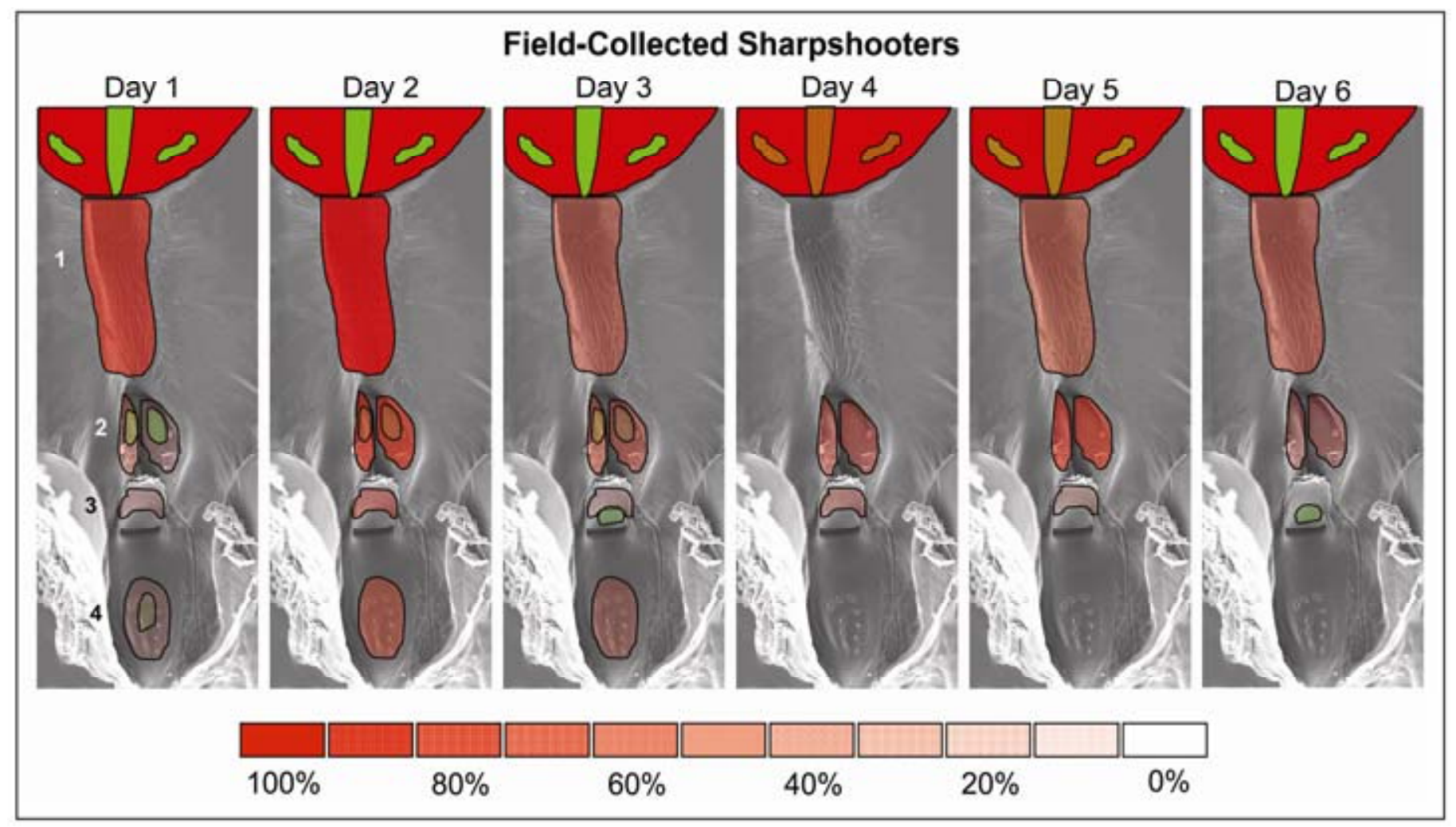

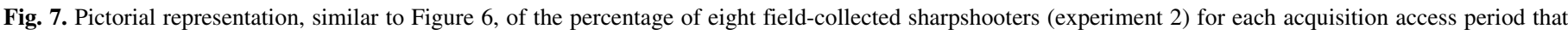

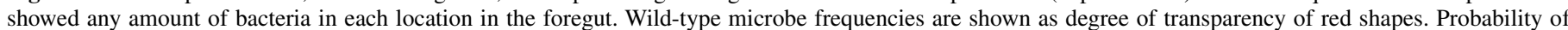

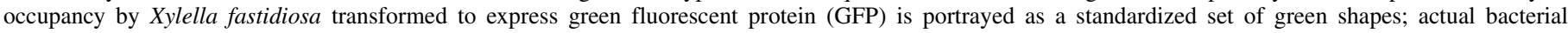

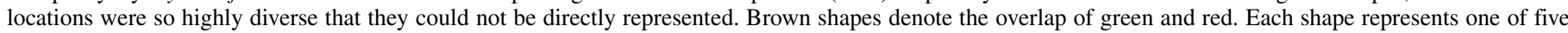

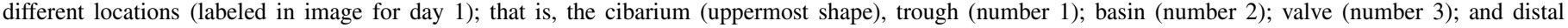

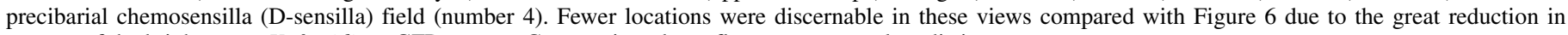
amount of the bright-green $X$. fastidiosa GFP present. Contrast in red autofluorescence was less distinct. 
Our work adds to that of previous $X$. fastidiosa studies by examining the undisturbed location of $X$. fastidiosa colonies in situ in the foregut and demonstrating (i) the means by which the precibarial valve malfunctions, by being affixed in an open position that prevents function as a pressure-sensitive check valve, thus allowing fluid to be egested out the stylets rather than swallowed; (ii) two possible mechanisms of egestion (rinsing and discharging) that each occur at different, overlapping times in the stylet penetration process $(3,4)$; and (iii) a spatiotemporal cycle of microbial acquisition into and egestion or inoculation from the precibarium.

The evidence presented herein is not definitive proof of the salivation-egestion hypothesis for X. fastidiosa inoculation. The present work does, however, indicate that at least one type of sharpshooter-controlled egestion (due to abnormal functioning of the precibarial valve) is likely to be critical for Xylella spp. inoculation behaviors.

Implications for vector efficiency of sharpshooters and microbial competition. Comparing acquisition results for clean, laboratory-reared versus field-collected $H$. vitripennis suggests that the earliest-acquired microbes successfully colonized the largest areas of the foregut. $X$. fastidiosa acquired by laboratoryreared $H$. vitripennis had ample binding sites available in an empty, or nearly empty, foregut. In contrast, the same strain of $X$. fastidiosa acquired by contaminated field-collected insects had much less space left to colonize. This finding provides evidence for competitive binding for optimum acquisition sites in the precibarium, from which egestion or inoculation would subsequently occur.

Many of the wild-type microbes we found resembled, and may have been, $X$. fastidiosa. However, other unknown microbes appeared to be different species. There may be competitive binding among Xylella and non-Xylella microbes in a diverse microbial community inside sharpshooter foreguts. Such competitive, even exclusionary, microbial binding could be one important reason for differences in efficiency of $X$. fastidiosa acquisition by sharpshooter vectors and, therefore, both vector competence and efficiency of inoculation. Indeed, other, preliminary, research suggests that inoculation success during a single sharpshooter probe is strongly dependent on acquisition success (2). Properties of microbial binding to cuticle and community diversity could partly explain why $G$. atropunctata readily acquires pure colonies of $X$. fastidiosa, while $H$. vitripennis (at least in California) may not (1; this study). In contrast, fieldcollected $H$. vitripennis in Florida (which recently have been shown to be genetically different from those in California) (13) acquire seemingly pure colonies of $X$. fastidiosa (8). Perhaps species richness of the xylem-dwelling microbial community in host plants varies among different geographical areas which, in turn, influences the microbial community structure in vector foreguts. Our results show that a mixture of microbe species can become established in vector foreguts. Yet, in the absence of competing microbes, $X$. fastidiosa can establish a near-pure colony in vector foreguts. Thus, host plant heterogeneity for $X$. fastidiosa infection titer and distribution in relation to other microbes likely influences sharpshooter vector load and subsequent $X$. fastidiosa inoculation efficiency.

\section{ACKNOWLEDGMENTS}

This project was supported by a grant from the University of California Pierce's Disease Research Program and in-house funding from the United States Department of Agriculture-Agricultural Research Service (ARS). We thank H. Shugart for performing all confocal and electron microscopy in this article; J. Gutierrez (ARS Parlier), M. Johnson (UCR), R. Krugner (then UCR, now ARS Parlier), and H. Kinney (CDFA Riverside) for collecting, rearing, and maintaining insects and plants for this work; G. Phillips, working with J. Chen (both ARS Parlier), for kindly maintaining $X$. fastidiosa GFP in culture and performing the PCR infection checks of mechanically inoculated grapevines; and R. Almeida (University of California, Berkeley), M. Sisterson, and J. Chen for providing useful and appreciated reviews of earlier drafts of the manuscript.

\section{LITERATURE CITED}

1. Almeida, R. P. P., and Purcell, A. H. 2006. Patterns of Xylella fastidiosa colonization on the precibarium of sharpshooter vectors relative to transmission to plants. Ann. Entomol. Soc. Am. 99:884-890.

2. Backus, E. A. 2007. How to be an ideal vector: four crucial steps in the transmission mechanism of Xylella fastidiosa by sharpshooters. In: Proc. 1st Annu. Natl. Viticulture Res. Conf. Davis, CA

3. Backus, E. A., Habibi, J., Yan, F. M., and Ellersieck, M. 2005. Stylet penetration by adult Homalodisca coagulata on grape: Electrical penetration graph waveform characterization, tissue correlation, and possible implications for transmission of Xylella fastidiosa. Ann. Entomol. Soc. Am. 98:787-813.

4. Backus, E. A., Holmes, W. J., Schreiber, F., Reardon, B. J., and Walker, G. P. 2009. Sharpshooter X wave: correlation of an electrical penetration graph waveform with xylem penetration supports a hypothesized mechanism for Xylella fastidiosa inoculation. Ann. Entomol. Soc. Am. 102:847-867.

5. Backus, E. A., and McLean, D. L. 1982. The sensory systems and feeding behavior of leafhoppers. I. The aster leafhopper, Macrosteles fascifrons Stål (Homoptera: Cicadellidae). J. Morphol. 172:361-379.

6. Backus, E. A., and McLean, D. L. 1982. The sensory systems and feeding behavior of leafhoppers. II. A comparison of the sensillar morphologies of several species (Homoptera: Cicadellidae). J. Morphol. 176:3-14.

7. Brault, V., Uzest, M., Monsion, B., Jacquot, E., and Blanc, S. 2010. Aphids as transport devices for plant viruses. C. R. Biol. 333:524-538.

8. Brlansky, R. H., Timmer, L. W., French, W. J., and McCoy, R. E. 1983. Colonization of the sharpshooter vectors, Oncometopia nigricans and Homalodisca coagulata, by xylem-limited bacteria. Phytopathology 73:530-535.

9. Brlansky, R. H., Timmer, L. W., and Lee, R. F. 1982. Detection and transmission of a gram-negative, xylem-limited bacterium in sharpshooters from a citrus grove in Florida. Plant Dis. 66:590-592.

10. Chen, J., Groves, R., Civerolo, E. L., Viveros, M., Freeman, M., and Zheng, Y. 2005. Two Xylella fastidiosa genotypes associated with almond leaf scorch disease in the same location in California. Phytopathology 95:708-714.

11. Daugherty, M. P., and Almeida, R. P. P. 2009. Estimating Xylella fastidiosa transmission parameters: decoupling sharpshooter number and feeding period. Entomol. Exp. Appl. 132:84-92.

12. Davis, M. J., French, W. J., and Schaad, N. W. 1981. Axenic culture of the bacteria associated with phony disease of peach and plum leaf scald. Curr. Microbiol. 6:309-314.

13. de Leon, J. H., Jones, W. A., and Morgan, D. J. W. 2004. Population genetic structure of Homalodisca coagulata (Homoptera: Cicadellidae), the vector of the bacterium, Xylella fastidiosa, causing Pierce's disease in grapevines. Ann. Entomol. Soc. Am. 97:809-818.

14. Dugravot, S., Backus, E. A., Reardon, B. J., and Miller, T. A. 2008. Correlations of cibarial muscle activities of Homalodisca spp. sharpshooters (Hemiptera: Cicadellidae) with EPG ingestion waveform and excretion. J. Insect Physiol. 54:1467-1478.

15. Fereres, A., and Moreno, A. 2009. Behavioural aspects influencing plant virus transmission by homopteran insects. Virus Res. 141:158-168.

16. Harris, K. F. 1977. An ingestion-egestion hypothesis of noncirculative virus transmission. In: Aphids as Virus Vectors. K. F. Harris and K. Maramorosch, eds. Academic Press, Inc., New York.

17. Harris, K. F., and Bath, J. E. 1973. Regurgitation by Myzus persicae during membrane feeding: its likely function in transmission of plant viruses by vectors. Ann. Entomol. Soc. Am. 66:793-796.

18. Harris, K. F., and Harris, L. J. 2001. Ingestion-egestion theory of cuticulaborne virus transmission. In: Virus-Insect-Plant Interactions. K. F. Harris, O. P. Smith, and J. E. Duffus, eds. Academic Press, New York.

19. Hill, B. L., and Purcell, A. H. 1995. Acquisition and retention of Xylella fastidiosa by an efficient vector, Graphocephala atropunctata. Phytopathology 85:209-212.

20. McLean, D. L., and Kinsey, M. G. 1984. The precibarial valve and its role in the feeding behavior of the pea aphid, Acyrthosiphon pisum. Bull. Entomol. Soc. Am. 30:26-31.

21. Nault, L. R. 1997. Arthropod transmission of plant viruses: A new synthesis. Ann. Entomol. Soc. Am.. 90:521-541.

22. Nault, L. R., and Ammar, E. D. 1989. Leafhopper and planthopper transmission of plant viruses. Annu. Rev. Entomol. 34:503-529.

23. Newman, K. L., Almeida, R. P. P., Purcell, A. H., and Lindow, S. E. 2003. Use of green fluorescent strain for analysis of Xylella fastidiosa colonization of Vitis vinifera. Appl. Environ. Microbiol. 69:7319-7327. 
24. Powell, G. 1991. Cell membrane punctures during epidermal penetrations by aphids: consequences for the transmission of two potyviruses. Ann. Appl. Biol. 119:313-321.

25. Purcell, A. H. 1989. Homopteran transmission of xylem-inhabiting bacteria. In: Advances in Disease Vector Research. K. F. Harris, ed. Springer-Verlag, Inc., New York.

26. Purcell, A. H., Finlay, A. H., and McLean, D. L. 1979. Pierce's disease bacterium: mechanism of transmission by leafhopper vectors. Science
206:839-841.

27. Uzest, M., Gargani, D., Drucker, M., Hebrard, E., Garzo, E., Cadresse, T., Fereres, A., and Blanc, S. 2007. A protein key to plant virus transmission at the tip of the insect vector stylet. Proc. Natl. Acad. Sci. USA 104:17959-17964.

28. Wayadande, A. C., and Nault, L. R. 1993. Leafhopper probing behavior associated with maize chlorotic dwarf virus transmission to maize. Phytopathology 83:522-526. 